\title{
Surveys of Population Samples for Estimating Crime Incidence*
}

\author{
By Albert D. Biderman
}

\begin{abstract}
A national survey and intensive surveys in three cities were undertaken for the President's Commission on Law Enforcement and Administration of Justice (hereinafter referred to as the National Crime Commission), to assess crime incidence by asking random samples of the public whether they had been victimized by crime. The major difficulties of these surveys arose from victimization's being an infrequent and usually not highly salient life event for most people. Even though these surveys found victimization to be far more common than suggested by national or local police statistics, they captured people's experiences selectively and incompletely. The immediate data from a victim survey naturally differ in form from police and other agency statistics. While these make the survey data distinctively instructive, they present problems for comparison with police statistics. Such comparisons as can be made suggest that a large volume of citizen complaints to the police are not reflected in published offense statistics.
\end{abstract}

Albert D. Biderman, Pl.D., Washington, D.C., is Senior Research Associate, Bureau of Social Science Research, Inc., Washington, D.C. He explored uses of crime statistics as social indicators in a recent monograph on Social Indicators and Goals (1966). His broader interest in the regulation of behavior by social codes is reflected in the books March to Calumny: American Prisoners in the Korean War (1963) and, as editor with Herbert Zimmer, The Manipulation of Human Behavior (1961).

* Preparation of this paper was assisted by a grant from the Russell Sage Foundation and draws upon research supported by the Office of Law Enforcement Assistance, U.S. Department of Justice. 
$A^{S}$ part of its assessment of crime in America, the National Crime Commission in 1966 sponsored the first intensive attempts to use surveys of samples of the general public for estimating the incidence of crime. One of the most widely quoted sentences in the Commission's assessment of crime has been: "These surveys show that the actual amount of crime in the United States today is several times that reported in the UCR." 1

Two sets of data amplifying this conclusion were reproduced from surveys by the report. The first (Table 1)

1 U.S., President's Commission on Law Enforcement and Administration of Justice, The Challenge of Crime in a Free Society, hereinafter referred to as General Report (Washington, D.C.: U.S. Government Printing Office, 1967), p. 21. "UCR" in the quotation is a reference to data reported annually in U.S., Department of Justice, Federal Bureau of Investigation, Crime in the United States: Uniform Crime Reports (Washington, D.C.: U.S. Government Printing Office, 1930[annually]). In the present paper, UCR will be used to refer to this annual and the Uniform Crime Reporting System that it employs. compared UCR crime rates with estimates from a National Opinion Research Center (NORC) survey of members of a national sample comprising 10,000 households. The person interviewed in each household had been asked whether he or anyone living with him had been a victim of a crime during the preceding twelve months. The surveys estimated the rate of person crimes to be twice as high as that of the UCR and more than twice as high for property crimes. A more extreme deviation of survey-derived estimates from those based on police data was shown in a chart (Figure 1) based on a survey by the Bureau of Social Science Research (BSSR) in high- and medium-crime-rate precincts in Washington, D.C. Here, with data restricted to adults and with victimization of business and transient victims excluded from police estimates, the survey rates for offense classes were from three to ten times the number contained in police statistics.

"How much crime is there?" is hardly a simple question; the sample-

TABLE 1-Comparison OF SuRvey and UCR Rates (PER 100,000 PopUlation)

\begin{tabular}{|c|c|c|c|}
\hline IndeX CRIMes & $\begin{array}{c}\text { NORC SURVEY } \\
1965-1966\end{array}$ & $\begin{array}{c}\text { UCR RATE FOR } \\
\text { INDIVIDUALS } \\
1965^{2}\end{array}$ & $\begin{array}{c}\text { UCR RATE FOR } \\
\text { INDIVIDUALS } \\
\text { AND ORGANIZATIONS } \\
1965^{\circ}\end{array}$ \\
\hline $\begin{array}{l}\text { Willful homicide } \\
\text { Forcible rape } \\
\text { Robbery } \\
\text { Aggravated assault } \\
\text { Burglary } \\
\text { Larceny ( } \$ 50 \text { and over) } \\
\text { Motor vehicle theft }\end{array}$ & $\begin{array}{r}3.0 \\
42.5 \\
94.0 \\
218.3 \\
949.1 \\
606.5 \\
206.2\end{array}$ & $\begin{array}{r}5.1 \\
11.6 \\
61.4 \\
106.6 \\
299.6 \\
267.4 \\
226.0\end{array}$ & $\begin{array}{r}5.1 \\
11.6 \\
61.4 \\
106.6 \\
605.3 \\
393.3 \\
251.0\end{array}$ \\
\hline $\begin{array}{l}\text { Total violence } \\
\text { Total property }\end{array}$ & $\begin{array}{r}357.8 \\
1,761.8\end{array}$ & $\begin{array}{l}184.7 \\
793.0\end{array}$ & $\begin{array}{r}184.7 \\
1,249.6\end{array}$ \\
\hline
\end{tabular}

a Crime in the United States: Uniform Crime Reports, op.cit., 1965, p. 51. The UCR national totals do not distinguish crimes committed against individuats or households from those committed against businesses or other organizations. The UCR rate for individuals is the published national rate adjusted to eliminate burglaries, larcenies, and vehicle thefts not committed against individuals or households. No adjustment was made for robbery. 


\section{Estimated Rates of Offense ${ }^{1}$ \\ Comparison of Police ${ }^{2}$ and BSSR Survey Data}

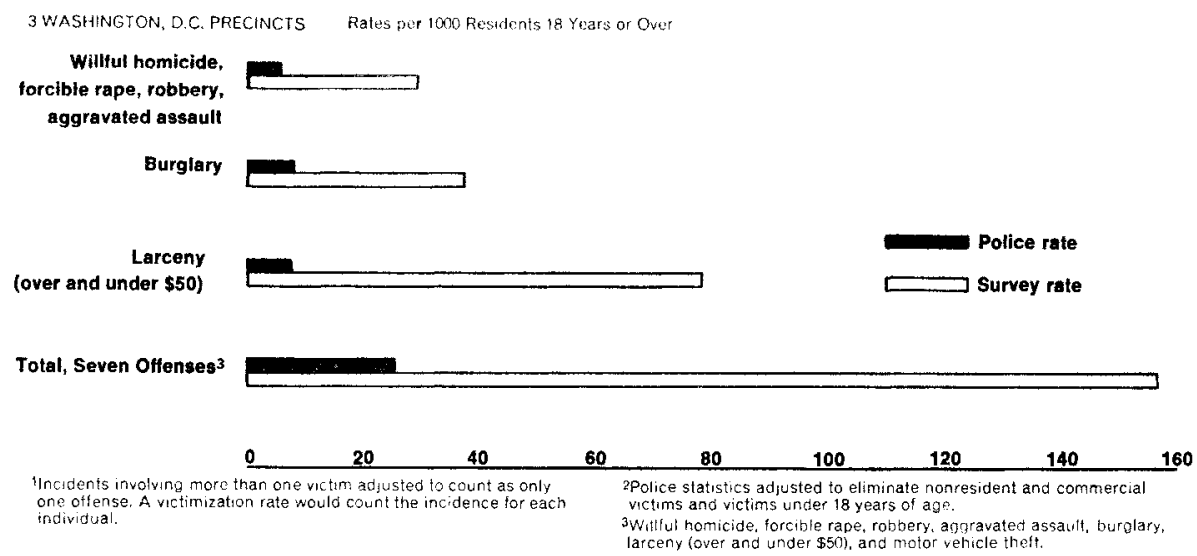

Figure 1

survey approach to answering it is fraught with complexities; and comparing survey estimates with those of the UCR can be performed only with some strain to both sources of data. This paper describes how the surveys in question dealt with these problems and the implications of their method for knowledge regarding the incidence of crime.

\section{Planning of the Studies}

The advisability of conducting an extensive, national, cross-sectional survey to estimate the incidence of crime was accepted early in the work-planning of the National Crime Commission. ${ }^{2}$ Its feasibility, however, was at issue. Paradoxically, an endeavor occasioned by an almost universally shared sentiment that crime was exceeding all bounds had to confront as its greatest planning problem the possibility that there might not be enough crime-that

2 The President's Commission on Crime in the District of Columbia had parallel interests in exploring crime in the capital. This led to early sponsorship of the surveys in Washington. is, not enough for it to be economically measurable by the sample-survey method. The UCR Crime Index for the most recent year showed a rate of only about fourteen Index crimes for every thousand persons in the population. A large and not precisely estimatable proportion of these involved offenses against businesses and other organizations. The latter, it was early concluded, could not be measured by a population crosssection survey, but rather required more complex and costly approaches. A national survey would have to be restricted to crimes against the private citizen or the residential household. Discouraging estimates still remained even after allowing for an appreciably large "dark figure" of crime and for the fact that the number of crime victims (or victimization rates) greatly exceed the number of offenses (or offense rates). ${ }^{3}$ The first crude estimates posited that something on the order of twenty adults per thousand nationally were victims of an Index crime in a given year, although

${ }^{3}$ See Albert D. Biderman and Albert J. Reiss, Jr., "On Exploring the 'Dark Figure' of Crime," in this issue of THe Annals, pp. 1-15. 
the rate might be as much as five times greater in high-crime urban areas.

These estimates presented the following implications for the use of the survey method that was being contemplated by the National Crime Commission during the Fall of 1965:

A very large population sample30,000 households or more-would have to be used to produce a sufficient number of recent incidents of victimization-

... Unless respondents could remember and report reliably on victimization that occurred over an extended period of their life, or

. . Unless one respondent could report reliably regarding the victimization for all members of a household, or

... Unless the volume of the "dark figure" that might be revealed by survey methods proved to be several times the magnitude of crimes known to the police.

The urgent time requirements of research undertaken for the Commission dictated a research strategy that hedged these possibilities. The Bureau of Social Science Research (BSSR) undertook an immediate effort, in conjunction with its precinct studies for the District of Columbia Crime Commission, to explore instruments and approaches which might also be used in a national study and for some indication of the frequencies of victimization which the interview might yield. ${ }^{4}$ At the same time, consulta-

${ }^{4}$ Albert D. Biderman, Louise A. Johnson, Jennie McIntyre, and Adrianne W. Weir, Report on a Pilot Study in the District of Columbia on Victimization and Attitudes toward Law Enforcement, U.S. President's Commission on Law Enforcement and Administration of Justice Field Survey I (Washington, D.C.: U.S. Government Printing Office, 1967). This "forced draught" study also prepared an early preliminary report on crime incidence in Washington for use tions were begun regarding the feasibility of employing for a national survey the only known agency with a ready capability for interviewing extremely large national population samples-the Current Population Survey of the Bureau of the Census, which regularly interviews a sample of respondents covering approximately 30,000 American households.

\section{Pretest Experience}

In its Washington pretesting, the BSSR study tried a number of differen1 question-orders and question-wordings Telephone interviews were also tried, but these were quickly found to yield many fewer recollections of having been a victim of an offense than door-bellringing interviewers were reporting. The latter's interviews, however, included many more reports of victimization than had been predicted. Over two-thirds of the Washington pretest respondents told of some criminal incident that had victimized their household at some time, and there was a very heavy concentration of these mentions in recent periods.

Additional evidence of the feasibility of using smaller samples became available to the Commission at the same time. In November 1965, independently of the pretest for the Crime Commission, the National Opinion Research Center (NORC) incorporated several questions on crime-victimization in one of its periodic national surveys. Of 1,520 households covered, 47 per cent reported

by the District of Columbia Crime Commission, which had to complete its work a half-year earlier than the National Commission: Albert D. Biderman et al., "Salient Findings on Crime and Attitudes toward Law Enforcement in the District of Columbia," Bureau of Social Science Research, Washington, D.C., May 1966 (Mimeographed). The studies were supported by the Office of Law Enforcement Assistance of the Depart. ment of Justice. 
having been victimized at one time or another, and 11 per cent had been victimized by something they considered a crime during the current year. ${ }^{5}$

\section{The Surveys for tile Commission}

Since both the NORC and the BSSR testing suggested that yet greater frequencies might be found with improvements in the interviewing procedures, and since it was still uncertain that the resources of the Census Bureau could be allocated to the project quickly enough to produce data for use by the National Crime Commission, the decision was made to have the national survey proceed with a smaller sample $(10,000$ households) and a private contractor, the NORC. ${ }^{6}$

BSSR pretests established that even very small samples of city residents would provide sufficient data on victimization for useful analysis. Intensive sampling in selected police districts of cities opened the way for analysis in terms of detailed information on the social characteristics of areas, the nature of police operations in these areas, and comparability with police statistics and data on crime from other special studies being planned by the University of Michigan for Washington, D.C., and other cities. ${ }^{7}$

5 Unpublished Memorandum from the $\mathrm{Na}-$ tional Opinion Research Center to the President's Commission on Law Enforcement and Administration of Justice, February 18, 1966.

${ }^{6}$ Philip H. Ennis, Criminal Victimization in the United States: A Report of a National Survey, U.S. President's Commission on Law Enforcement and Administration of Justice Field Survey II (Washington, D.C.: U.S. Government Printing Office, 1967).

${ }^{\tau}$ For a description of the integrated studies of crime by the University of Michigan, see Albert J. Reiss, Jr. (ed.), Studies in Crime and Law Enforcement in Major Metropolitan Areas, Vol. I, U.S. President's Commission on Law Enforcement and Administration of Justice Field Survey III (Washington, D.C.: U.S. Government Printing Office, 1967).
BSSR continued with its pilot study employing a sample of 511 residents of three police precincts in Washington, D.C. Procedures developed in this survey were improved and adapted for surveys of victimization that were conducted by Albert J. Reiss, Jr., of the University of Michigan, covering 600 households in two police districts in each of two other cities (Boston and Chicago). ${ }^{8}$ BSSR also used this modified procedure in an additional Washington police precinct in which 282 residents were interviewed. The precincts showed medium to high crime rates in police data. Three of the Washington precincts and one of those chosen in both Boston and Chicago ${ }^{\circ}$ had predominantly nonwhite populations. Table 2 summarizes the dimensions of these studies.

The objectives of the surveys went considerably beyond exploring the "dark figure" of crime. For each incident, respondents were questioned on when, where, how, and why the offense had taken place; on characteristics of the offenders; on the extent and nature of losses and recovery or indemnification for these; and on investigatory and adjudicatory processes that ensued. All of this information regarding victimization could be related to detailed information that was also collected in the surveys on social-background characteristics of the victims; their attitudes toward many issues relating to crime, law enforcement, and justice; and some

8 Ibid. The victimization interview was further adapted by the University of Michigan for questioning representatives of business and other organizations in Boston, Chicago, and Washington.

${ }^{9}$ During the course of the study in one of the Chicago districts, a serious riot occurred in the area. Its effects on the data of the study are probably very pronounced. Data from this area, consequently, are omitted from the present discussion. 
TABLE 2-1966 SuRveys OF Victimization

\begin{tabular}{|c|c|c|c|c|}
\hline Study Name & Area SAMPLed & $\begin{array}{l}\text { SAMPLED } \\
\text { UNITS }\end{array}$ & $\begin{array}{l}\text { TYPE OF SAMPLE } \\
\text { AND INFORMANT }\end{array}$ & $\begin{array}{l}\text { VICTIM- } \\
\text { IZATION } \\
\text { INTERVIEWS }\end{array}$ \\
\hline NORC "AMALGGAM" & Nation & 1,520 & $\begin{array}{l}\text { Household-any adult } \\
\text { as screener re- } \\
\text { spondent }\end{array}$ & $\begin{array}{l}714 \\
(71)^{a}\end{array}$ \\
\hline BSSR Pretest & $\begin{array}{l}\text { Washington, D.C. } \\
\text { (11 precincts) }\end{array}$ & 183 & Household-any adult & 84 \\
\hline BSSR Pilot & $\begin{array}{l}3 \text { Washington, D.C. } \\
\text { precincts }\end{array}$ & 511 & $\begin{array}{l}\text { Randomized adult in } \\
\text { sampled households }\end{array}$ & $\begin{array}{c}444 \\
(195)\end{array}$ \\
\hline BSSR Supplement & $\begin{array}{l}1 \text { Washington, D.C. } \\
\text { precinct }\end{array}$ & 282 & $\begin{array}{l}\text { Randomized adult in } \\
\text { sampled households }\end{array}$ & $\begin{array}{l}544 \\
(208)^{\mathrm{a}}\end{array}$ \\
\hline \multirow[t]{2}{*}{$\begin{array}{l}\text { University of Michigan } \\
\text { "Resident" }\end{array}$} & $\begin{array}{l}2 \text { Boston police } \\
\text { districts }\end{array}$ & 351 & $\begin{array}{l}\text { Randomized adult in } \\
\text { sampled households }\end{array}$ & $(224)^{a}$ \\
\hline & $\begin{array}{l}2 \text { Chicago police } \\
\text { districts }\end{array}$ & 244 & $\begin{array}{l}\text { Randomized adult in } \\
\text { sampled households }\end{array}$ & $(91)^{\mathrm{a}}$ \\
\hline $\begin{array}{l}\text { University of Michigan } \\
\text { "Business and } \\
\text { Organization" }\end{array}$ & $\begin{array}{l}\text { Washington, Boston, } \\
\text { Chicago }\end{array}$ & 768 & $\begin{array}{l}\text { Representatives of } \\
\text { business and other } \\
\text { organizations }\end{array}$ & 333 \\
\hline $\begin{array}{l}\text { University of Michigan } \\
\text { "Known Victims" }\end{array}$ & $\begin{array}{l}\text { Washington, Boston, } \\
\text { Chicago }\end{array}$ & 400 & $\begin{array}{l}\text { Persons observed } \\
\text { making complaint } \\
\text { to police }\end{array}$ & 400 \\
\hline NORC & Nation & $10,000^{\mathrm{b}}$ & $\begin{array}{l}\text { Household-any adult } \\
\text { as screener re- } \\
\text { spondent }\end{array}$ & $\begin{array}{l}3,146 \\
(2,081)^{\mathrm{a}}\end{array}$ \\
\hline
\end{tabular}

${ }^{a}$ Used in making twelve-month incidence rate estimates.

b Representing 33,000 members of these households.

other relevant aspects of their experience and behavior.

Because of the great attention that has been given to the matter of gross estimates of crime incidence, however, attention will be directed here exclusively to examining the procedures bearing on this aspect of the surveys. ${ }^{10}$ Examining the methodological problems carefully is important for three reasons. First, any enthusiasm for this innovational method that may derive from its success at demonstrating the existence of a vast "dark figure" of crime should be tempered by recognition of the limited refinement thus far achieved in applying the data to description and interpretation of dimensions of the crime

\footnotetext{
${ }^{10}$ Some findings from the survey relating to attitudes are discussed in Jennie McIntyre, "Public Attitudes toward Crime and Law Enforcement," in this issue of THE AnNals, pp. 34-46.
}

picture. Second, the cross-sectional survey affords data on crime that differ in some key and instructive respects from agency statistics. ${ }^{11}$ Third, understandings developed regarding some major methodological problems yielded some understandings about crime equally as interesting as those yielded by application of the method to the problem of gross estimation.

\section{Problems of Recall}

An assumption that guided the planning of the work followed from the dramatic connotations of the word "crime." It was assumed that most "Index" crimes, as well as a large number of other types of offenses, would be very salient events in the victims' lives. There was some confidence that a survey respondent would be able to

${ }^{11}$ See Biderman and Riess, op. cit. 
recall the occurrence of such incidents for a considerable span of time, even though he might not be able to remember many particular details of the event. The assumption that much crime-victimization is an event as readily recalled as births, deaths, or marriages in the family was proved unfounded.

\section{Time And Incident Mentions}

In testing interview methods, the number of incidents mentioned by the average respondent increased as more specific and focused questions about victimization were tried. Asking about specific types of events, persons affected, and time periods proved particularly important. This effect is so marked that about the same volume of reports of victimization were yielded in BSSR pretests by asking people what had happened to them during only the most recent year as by asking them whether they had ever been victimized. The effect of not focusing the recall of the respondent on a particular time period may explain the results of a privately conducted national poll, published in July 1966, which used a "Were you ever ... .?" type of question. Only one of every eleven adults in the sample told of having ever been victimized in response to this questionslightly fewer than the response rate to an NORC question which asked about the past twelve months only. ${ }^{12}$

The effect of lack of time focus in a question is distinguishable from the effects of the passage of time on respondents' ability to recall incidents within the limited opportunities for reflection the interview affords. Respondents in all of the surveys mentioned many more recent incidents than older ones. BSSR preliminary interviewing

12 Louis Harris, "The Nation: Eye-for-anEye Rule Rejected," Washington Post, July 3, 1966, p. E3. which used members of the research organization as subjects was particularly instructive. In each case, these people reported back hours, days, and even weeks later about incidents that they had not remembered at the time they were first interviewed. This recency effect was markedly evident within the one-year period which all three surveys used as a basis for forming rate estimates. It also was found when responses to questions covering longer time spans were tabulated-for example, responses to a BSSR question about the worst crime that the respondent had ever experienced. The effect was far more pronounced than can plausibly be attributed to any over-all trend or seasonality in crime incidence.

Using a short recall-span for rateestimation would compensate for forgetting on the part of respondents, but it assumes no seasonality or long-term trends in the "true rate" of crime. Were victimization rate estimates to be based only on incidents in the most recent six-month period and this rate projected to an annual one, the several studies would yield estimates 25 to 30 per cent greater. The difference would be even more pronounced if rates were estimated from the incidents of just the most recent three months of the NORC data - the result would be a 60 per cent greater estimate. This is partly a consequence of another distortion in interview testimony, which we will next discuss.

\section{Time Telescoping}

The time distributions of respondents' reports were complicated by a problem regularly encountered in surveys asking people to recount life events. This is called "time telescoping," although the term is used to describe the person's recalling an event as having happened less recently than was actually the case as well as to describe forward shifting 
of the recall. ${ }^{13}$ A particular hazard of "telescoping" is that respondents may sometimes tend to shift events that happened before or after a time interval about which they are asked into that interval. The distribution of incidents in the national survey had a bulge at the beginning of the twelve-month period regarding which respondents were asked to report. But this was a much less pronounced bulge than that at the recent end of the distribution. This " $J$ " shape suggests that both recency and telescoping effects operated, with the former being more pronounced. The BSSR and Michigan surveys controlled telescoping, at least partially, by asking respondents to report events covering a period extending further at both extremes than the twelve months used for estimation purposes. While avoiding the "J" shape, the wider time-focus in the questioning presumably makes recall more difficult.

Although it is theoretically possible to use the survey method for a measure of the entire life experience of each respondent (which, in turn, could be converted into an historical measure for the entire population), in practice this would presumably require, to say the least, very time-consuming interview methods.

\section{Seriousness}

Another assumption altered by the actual experience of these surveys was that respondents would report minor and even trivial incidents of victimization in high proportion. Indeed, in line with the objective of having the surveys supplement police statistics as much as possible, a number of features of the interviewing procedure explicitly

13 U.S., Bureau of the Census, Response Errors in Collection of Expenditures Data by Household Interviews: An Experimental Study, Technical Paper No. 11 (Washington, D.C.: U.S. Government Printing Office, 1965). encouraged the respondent to report "even little things." (Interviewers defined crime for the respondents as: "Anything somebody could be sent to prison or fined for doing to you- or even for trying to do it.") In the BSSR pilot study, however, with the exception of auto theft and malicious destruction of property, which figure more frequently in survey data, the classes of offenses reported by survey respondents had close to the same rankorder as did police data for victim-type offenses for the same precincts. As was shown in Table 1, NORC's national sample had a rank-ordering of mentions of Index offenses quite similar to that in the UCR Crime Index.

The average loss in burglaries reported by NORC's respondents was $\$ 190$, considerably below the over- $\$ 260$ figure of the UCR. ${ }^{14}$ Of the larcenies in the BSSR survey data, however, a higher proportion involved claimed losses of over $\$ 100$ than was true of police data for the same Washington precincts. This may be due to victims' tendencies to attribute higher value to losses than would be the case in police estimates.

When a "seriousness scale" for crimes, developed by Sellin and Wolfgang, ${ }^{15}$ was applied, the mean score for each frequent class of offense described by BSSR survey victims was very close to that computed from a large number of Philadelphia arrest records used in developing the original measure.

In the BSSR pilot study, 55 per cent of the described incidents were classified as Index offenses, and almost twothirds were Part I offenses. Only about one-third of the incidents in the national survey involved Index crimes,

${ }^{14}$ Crime in the United States: Uniform Crime Reports, 1965, op. cit., p. 105.

15 Thorsten Sellin and Marvin E. Wolfgang, The Measurement of Delinquency (New York: John Wiley \& Sons, 1964). 
quite possibly because these are more characteristic of big-city victimization.

It had also been assumed that some types of serious victimization might not be mentioned because of negligence or contributory behavior on the victim's part or because of embarrassment in the case of sex offenses. In the BSSR study which asked about this specifically, in about 25 per cent of the cases victims acknowledged that their negligence (11 per cent) or some act of commission on their part had contributed to their victimization. With regard to reticence from embarrassment, the precinct studies found much higher volumes of sex offenses (often described in frankest detail) than expected on the basis of police data. While these usually involved voyeurism or exhibitionism, molestations and rapes were mentioned with some frequency.

\section{HoUSEHOLd INFORMAN'S}

The assumption of the experiential salience of victimization made it appear promising to use any responsible person first contacted in a sampled household as an informant for all crimes against members of that household. Despite some expected losses of information in cases where members of the same household may be inclined to keep victimization secret from one another, this procedure affords vast gains in economy for what, at its most economical, is a very expensive data-collection method. Also recommending the household-informant method is that most offenses against private citizens can be regarded as victimizing all members of the household simultaneously, so that, theoretically, any responsible member of the house would be about as good a source of information regarding the event as any other member. In the BSSR pilot study, two-thirds of all recent incidents of victimization were classed, although often somewhat arbitrarily, as victimizing the household as a whole.

In the case of offenses against individuals, however, BSSR pretests found that the people interviewed about crimes in their household mentioned incidents of which they themselves were the victim in great disproportion to incidents affecting others who lived with them. For this reason, the BSSR and Michigan studies used interviews with a designated, randomly selected adult within each sampled household. Although these respondents were also asked to provide data on victimization of other individuals, primary attention in analysis was given to the victimization of the respondent, either as an individual or as a member of a victimized household. The inefficiency of questioning about other members is indicated by the finding that there was no positive correlation found in the BSSR study between the size of household and the number of incidents reported by the respondent.

The national study, for reasons of economy, used the most readily available adult as the household informant rather than randomly selected ones. The strategy was to identify from this "screener" respondent those members of the household who had been victimized during the previous twelve months. Call-backs were then made, as necessary, to gain detailed information about the individual incidents from the actual victim.

As was found in the BSSR tests, the NORC household "screener" respondents identified themselves as personal victims of offenses more frequently than they mentioned incidents against other household members. For the two offenses involving individuals as victims for which data are given-assault and robbery-twice as many of the incidents were against the 48 per cent of the adult householders who were household informants as against the other adult 
members. The effect was even more pronounced for Negro households. The resulting distortion is greater than these figures suggest. Housewives and other nonemployed persons, who are much more likely to be the person at home when an interviewer calls, would also be expected to be much less often victims of these offenses. Presumably as a result of this aspect of the procedure, NORC data show, for example, females victimized more often by assault and robbery than males. Other comparisons of victimization rates by personal characteristics of the victims, such as age, sex, education or occupation, are rendered equally suspect for the same reason.

Less affected are analyses of characteristics that victims share in common with all members of their family, such as family income, place of residence, or occupation of the head of the household. Here the distortion from use of "screener" informants is significant only by inflation or deflation of victim rates for categories of families depending upon the differential likelihood of a high-risk member or a low-risk member being the adult first contacted by the interviewer. Thus, unattached males would be expected to show artifactually inflated rates of person crimes relative to family breadwinners, and the same would be the case with members of households consisting solely of adults working full-time.

For offenses victimizing the entire household, such as vandalism or burglary, the nonrandom selection of the screener informant was also of less consequence to the NORC results. (The BSSR studies, however, found some tendency for women to mention more incidents affecting household property than was the case when a man was interviewed, as might be expected, given the woman's special role in the home.)

In analyzing victimization data by characteristics of the victims, only the head of the household was considered the victim in the analyses of the national study. Among the distortions resulting from this procedure is a vast overstatement of male victimization relative to female in several classes of crime, including burglary, larceny, auto theft, auto offenses, and malicious mischief. White males, for example, are shown as being burglary victims over six times as frequently as white females. This defect of the statistics can readily be overcome in future analysis where deadlines are less urgent. Characteristics of all household members can be counted for household offenses; or analysis can be made of such incidents exclusively in terms of household units rather than persons.

In the case of distortions of victim characteristics in individual-type offenses, as well, the NORC collected data which will permit some degree of correction of the distortion in future analyses. These included questionnaires completed for a sample of persons not identified by "screener" respondents as victims.

\section{SELECTIVITY IN UNDERREPORTING}

Victimization rates, as measured by the survey, thus may vary among various categories of respondents because of differences in their behavior as interview subjects, as well as because of differences in their actual experience with crime. The disposition and ability to recall events, co-operativeness with the interviewer, and different understandings of what constitutes a crime may affect the number and types of incidents a given respondent reports. His role in the household, apparently, has much to do with what he (more frequently, she) reports as an informant about other members. That the survey reflects far more of all episodes of criminal victimization that occur in the commu- 
nity than do police statistics provides no guarantee that it does so less selectively as among categories of respondents or crime classifications. Data from these surveys, therefore, cannot answer satisfactorily the question of why some kinds of people are more prone to victimization than are others until there are at least some good answers to the question of why some people are more likely to mention victimization when asked about it in a certain way by a survey interviewer. The situation is analagous to alternative interpretations of police statistics as reflecting both reporting behavior and victimization.

\section{Class-linked underreporting}

The problem of interpretation may be clarified by examining the relation of social-class variables to the number of incidents of victimization mentioned by survey respondents.

It is generally taken for granted that crime-at least the common offenses that figure in the Crime Index-is most prevalent in lower-class areas. Criminality is believed to be inversely related, statistically, to most dimensions of social-class standing. Older studies suggest that victims tend to resemble offenders for many crimes, since criminals tend to be homeoaggredic: slum dwellers tend to victimize slum dwellers, sons victimize fathers, gamblers other gamblers, and the like.

The results of the several surveys were inconsistent with such hypotheses in many respects, if survey victimization rates are interpreted literally. The BSSR survey found the frequency of mentions of incidents of victimization directly related to most social-classlinked variables that it tested. More victimization was reported by homeowners than renters; by residents of single-family structures and elevator apartments than those in walk-ups or rooming houses; by residents of sound structures rather than dilapidated or deteriorating ones; by those paying higher rentals; by members of intact families as compared with unattached individuals; and the like. The most discriminating variable of all was education, but a sharp break was discernible only at the level of college education. College-educated respondents reported more frequent victimization than others.

Some of these distributions by socialclass related variables, however, had a noticeable hump at the bottom of the class scale. When unambiguously lowsocioeconomic-status respondents were differentiated on the basis of income, occupation, and education, their victimization rate was greater than that among the "middle-class," but slightly less than that of the highest-level subjects.

A plausible interpretation of these results is that victimization mentions in the survey were functions of both the degree of real exposure and the "productivity" of the respondent as an interview subject. ${ }^{16}$

Comparison of rates in reports of the national survey are more difficult to examine for possible interview effects because the data are not presented in terms of a rate per actual respondent. Nonetheless, data reported by NORC on crime incidence by race and income are generally similar to those of BSSR (Table 3). Whites have higher survey

${ }^{16}$ Other research, however, suggests the possibility that the higher-socioeconomic-level respondents in the particular areas studied may have high victimization rates. High rates for such offenses as burglary have been found in police statistics for upper-income census tracts contiguous to very low-income ones-a situation characteristic of the residence of all high-socioeconomic-status respondents in the BSSR study. See Sarah L. Boggs, "Urban Crime Patterns," American Sociological Review, Vol. 30 (December 1965), pp. 899-909. 
incidence rates than Negroes. The higher the income, the higher the survey victimization rate for both racial categories. Lower-income respondents and, more pronouncedly, nonwhites, tend to report victimization by Index offenses in greater proportion than the (usually) less serious non-Index offenses. In the case of Index offenses, for both whites and nonwhites, there is a decided dip in rates at the middle of the income distribution. Nonwhites have higher Index victimization rates than do whites.

That this is probably due to greater "productivity" in the interview situation of the higher-income (and usually better-educated) respondent is suggested by examination of larceny victimization. One would expect that, when victimized by a larceny, the less wealthy person or household would be less likely to suffer a loss above $\$ 50$ than the wealthier ones. In NORC's data, however, a higher proportion of all larcenies affecting those with family incomes under $\$ 6,000$ are Index larcenies than in the case of thefts from those with higher incomes. A similar interpretation may account for nonwhites reporting many more aggravated assaults than simple assaults.

The simple rank-ordering of classes of offenses by frequency of mentions in the national survey is presumably affected by various output restrictions of the interview method, so that more recent, more serious, more conventionally "criminal," and less embarrassing kinds of victimization are more likely to be mentioned. (The BSSR survey found rates for more recent incidents less class-linked than those for older ones.) Some of these factors doubtless affect total interview productivity more than others. Thus, there were as many rapes reported as incidents of victimization by bad checks, counterfeit money, or other forgeries combined; twice as many burglaries as victimizations by drunken or negligent driving; about the same number of burglaries as cases of malicious mischief; many more aggravated assaults than consumer frauds; and the like ${ }^{17}$ (see Table 4).

\section{OTHER RESTRICTIONS OF RESPON- DENTS' REPORTS}

In addition to the expense of lengthy interviews to a study, questioning regarding victimization can be extremely time-consuming for a frequently victimized respondent. In the national survey, NORC limited interviewing of any victim to two incidents. This pro-

${ }^{17}$ A slight distortion in the direction of more serious offenses results from the procedure of eliminating less serious offenses in interviewing respondents who reported more than two incidents.

TARLE 3-Per Capita Crime Incidence by Race and Income

\begin{tabular}{|c|c|c|c|c|c|c|c|}
\hline \multirow{2}{*}{ CRime } & \multicolumn{4}{|c|}{ White } & \multicolumn{3}{|c|}{ Nonwhite } \\
\hline & $\$ 00-$ & $\begin{array}{l}\$ 3,000- \\
\$ 5,999\end{array}$ & $\begin{array}{l}\$ 6,000- \\
\$ 9,999\end{array}$ & $\begin{array}{l}\text { Above } \\
\$ 10,000\end{array}$ & $\begin{array}{l}\$ 0- \\
\$ 2,999\end{array}$ & $\begin{array}{l}\$ 3,000- \\
\$ 5,999\end{array}$ & $\$ 6,000+$ \\
\hline $\begin{array}{l}\text { Index Offenses } \\
\text { Non-Index Offenses } \\
\text { All Offenses }\end{array}$ & $\begin{array}{l}.021 \\
.040 \\
.061\end{array}$ & $\begin{array}{l}.022 \\
.042 \\
.064\end{array}$ & $\begin{array}{l}.017 \\
.046 \\
.063\end{array}$ & $\begin{array}{l}.022 \\
.048 \\
.070\end{array}$ & $\begin{array}{l}.029 \\
.021 \\
.050\end{array}$ & $\begin{array}{l}.026 \\
.024 \\
.050\end{array}$ & $\begin{array}{l}.034 \\
.035 \\
.069\end{array}$ \\
\hline $\begin{array}{l}\text { Population of } \\
\text { Sampled Households }\end{array}$ & $(3,435)$ & $(6,573)$ & $(9,555)$ & $(5,897)$ & $(1,797)$ & $(1,665)$ & $(827)$ \\
\hline
\end{tabular}

- Based on Ennis, op. cit., p. 31. 
TABLE 4-Victimization Incidents UsEd to Estimate Crime Rates (NORC National SAMPLE)*

\begin{tabular}{|c|c|c|}
\hline Class & $\begin{array}{c}\text { NtMBER } \\
\text { OF } \\
\text { INCIDENTS }\end{array}$ & $\begin{array}{c}\text { Estimate } \\
\text { RATE } \\
\text { PER 100,000 } \\
\text { PoPULATION }\end{array}$ \\
\hline Homicide & 1 & 3.0 \\
\hline Forcible Rape & 14 & 42.5 \\
\hline Robbery & 31 & 94.0 \\
\hline Aggravated Assault & 71 & 218.3 \\
\hline Simple Assault & 130 & 394.2 \\
\hline Burglary & 309 & 949.1 \\
\hline Larceny ( $\$ 50$ and over) & 197 & 606.5 \\
\hline Larceny (under $\$ 50$ ) & 472 & $1,458.6$ \\
\hline Auto Theft & 68 & 206.2 \\
\hline Auto Offense & 145 & 445.8 \\
\hline Malicious Mischief & 344 & $1,061.3$ \\
\hline Forgery-Counterfeiting & 14 & 42.5 \\
\hline Fraud & 80 & 251.7 \\
\hline Consumer Fraud & 38 & 121.3 \\
\hline Other Sex Crimes & 45 & 142.5 \\
\hline Family & 85 & 206.2 \\
\hline Soliciting a Bribe & 3 & 9.1 \\
\hline Building Violations & 14 & 42.5 \\
\hline Kidnapping & 4 & 12.1 \\
\hline Other Victimization & 17 & 51.6 \\
\hline Total & 2,082 & $6,359.0$ \\
\hline
\end{tabular}

- Frequencies are taken from p. 108, rates from pp. 8 and 11, Ennis, op. cit. No attempt has been made to adjust slight discrepancies between frequency and rate.

duced some artificial reduction of the victimization rates presented.

Although the BSSR and Michigan surveys imposed no such ceiling, there is some indication that, consciously or unconsciously, the respondents themselves effected limits. One evidence of this effect observed in the pretest was an implausibly low number of cases reporting multiple incidents of victimization, that is, a high proportion of all respondents had no victimization at all to mention, or else reported just a single incident. These concentrations were regarded as implausible by considering hypothetical probability distributions of victimization. One such model assumes a constant and equal probability of victimization for all respondents, which would be true were people completely passive agents and if criminals selected victims randomly. If the more plausible assumption is made that some people are more victimization-prone than others, a yet greater proportion of cases of multiple victimization can be expected. (Operating in the opposite direction would be "once bitten, twice shy" tendencies, however, which would cluster cases around one incident.)

Successive revisions of the interviewing approach in pretests, the pilot study, and the supplemental study produced greater proportions of respondents reporting multiple victimization. Judging from the impressions of interviewers, however, even the final instrument, which yielded data consistent with a probability model assuming differential proneness to victimization among the population, still suffered from some output restriction. Interpretations of experience in the interview situation suggested that a certain point is reached when a respondent no longer feels he is being unco-operative if he chooses not to rack his brains further and says: "No, there was nothing else that happened."

\section{INCIDENCE OF VICTIMIZATION}

The interviews with household "screener" respondents by NORC produced about 4,000 reports of victimization among the 33,000 persons covered by the household sample. One-fifth of these incidents were not followed up successfully with an interview of a victim (or an adult informant, in the case of a juvenile victim) to produce the data required to evaluate and analyze the incident. These evaluations, in turn, resulted in rejecting about 1,000 more of the incidents as not meeting one or another criterion for judging whether a crime had indeed occurred during the appropriate one-year period against the person or personal property of a mem- 
ber of the household. The incidence estimations, thus, rested on just somewhat over half of the originally mentioned victimizations.

For each of the person offenses, the numbers are so small as to afford little confidence that successive samplings would not yield estimates very much higher or lower than those reported. Among the Index offenses, only burglary and larceny are numerous enough to permit reliable cross-tabulations going much beyond dichotomies. The NORC sample yielded twice as many incidents of victimization that were not in the Index classes, however. The over 2,000 incidents of victimization of all types which were available afford many possibilities for grouping for analytic purposes (see Table 4).

The precinct studies had even more severe limitations because of small numbers.

Including all types of offenses, there were about 6.3 incidents of crime counted for every 100 persons ${ }^{18}$ in the national sample during the twelve months, July 1965 through June 1966. Only 691 of the incidents used in the analysis were Index offenses, so that the incidence rate for these crimes was only .02 . The bulk of these Index incidents involved burglary and larceny-there were but 117 Index offenses involving force, violence, or threats thereof-or an incidence rate for such offenses of under .004 .

The methodology used in the precinct studies, and in all probability the higher crime incidence of the areas studied, resulted in their yielding much higher rates.

For each respondent in the BSSR and Michigan studies, there were almost

\footnotetext{
18 This differs slightly from an offense rate to the extent that persons not members of the sampled household may have been among the multiple victims of robberies and certain Part II incidents.
}

ten times as many incidents of victimization reported and accepted as valid as in the national study. Including all types of crime, the range among the precincts in the Michigan survey was from .73 victimizations per respondent per year in a Boston district to a low of .43 in Chicago. The BSSR pilot survey had comparable rates--the range was from .35 to .41 in three Washington precincts, and the supplemental BSSR study in a fourth Washington precinct had a victimization rate of .75 . About 45 per cent of the incidents in the precinct studies were Index crimes.

But this does not mean that victimization was ten times as frequent among the residents of the three cities as in the national survey. First of all, the precinct-study estimations deal exclusively with persons over seventeen years of age. Few of the offenses against individuals in the NORC study occurred to the one-third of the sample that is under this age.

Even more important is the fact that precinct studies involve a sample of only one person in each household. For household offenses, there are as many putative victims as there are household members. Thus, for these offenses, the victimization rate is, very roughly, 3.3 times as great as an incidence rate based on all members of the sample and about twice as great if just the adult population rate is desired. Since the large majority of the Index offenses are of this kind, the national survey victimization rate ${ }^{19}$ for Index crimes is in excess of .05 as contrasted with the per capita offense rate of .02 .

An additional understatement of the national rate by about 12 per cent may be inferred from descriptions of the procedure. This resulted from members of the sampled households who could not be reached for victimization inter-

${ }^{19}$ See discussion of "victim risk rates" in Biderman and Reiss, op. cit. 
views being retained in the base on which rates were calculated, as well as from arbitrarily limiting interviews to two incidents for any person. ${ }^{20}$

\section{Comparison with Police Statistics}

Despite the presumed tendency toward underestimation, the survey consistently found victimization more frequent than police statistics led one to suspect. It was no simple matter, however, to provide a quantitative expression of just how much greater the survey incidence was. This was true despite the fact that in design and analysis the surveys had been adapted to the problem of providing the readiest comparison with police data-these adaptations often entailing departures from the most logical or efficient survey procedures. ${ }^{21}$ Most of the difficulties of comparison derive from the fact that the basic unit of police statistics is the offense; that of the survey is the victimization experience of the individual citizen. Victim risk estimates are derived readily from survey data; offense rates, only by using corrections based on assumptions or extrinsic and often not ideally suitable data. A second source of difficulty in comparisons is separating offenses against businesses and organizations from those against individuals in police data. The local area surveys face the additional diffculty of comparing data collected from victims at their place of residence with police data that are organized by the location of the offense. While in an astonishingly high proportion of the cases, victimization was found by the surveys to take place at or close to home, only in Washington, D.C., could

${ }^{20} \mathrm{~A}$ very slight underestimation of rates derives from only one victim being counted by NORC in the occasional incident wherein more than one member of the household is victimized by a crime against the person.

21 Biderman and Reiss, op. cit. any adjustment be made readily to eliminate victimization of transients from police data (and the data available for this correction were far from ideal for the purpose). In addition, victimization of persons in the sample that occurred outside of their area of residence had to be omitted in comparisons. The precinct studies, furthermore, had to restrict comparisons to victimization of adults.

Perhaps the major source of noncomparability stems from the necessity of the surveys' acceptance of victim testimony at its face value while the police function as more than passive recorders of citizen offense reports. Several procedures were applied by the surveys to come as close to the legal and evidentiary evaluations of the respondents' reports as police might make, short of actual investigation.

Interviewers' subjective impressions regarding the respondent's veracity and his demeanor in relating details of a particular incident were used. Interview records were examined for inconsistencies and implausibilities. In addition to these tests being extremely unreliable, neither cast doubt on substantial numbers of the claimed victimizations-in the NORC survey, only 0.4 per cent were "unfounded" on these grounds. Many more alleged incidents were rejected for tabulation because the respondent's description did not assert sufficient evidence that a crime had occurred, for example, that the wallet had not been lost negligently, that the incident was not more appropriately classifiable as a fight than as an assault. Expert judgments were also applied for evaluating incident descriptions on evidentiary and legal criteria-policemen (NORC) and lawyers (NORC and Michigan) were used.

The foregoing recital does not exhaust the definitional and operational complexities that should caution com- 
parisons between crime as measured by the surveys and as measured by the police. Comparisons, it should be stressed, become possible only by what amounts to some coercion of either or both sets of data from their most natural form and fullest scope.

\section{Comparisons of Offense Rates}

As was shown in Table 1, the total rate for offenses against individuals and residences estimated from the survey is more than twice that of the UCR. This indication of the great volume of unrecorded Index crime is particularly striking, in that almost all procedural failings of the survey method which have been identified in the preceding discussion tend to lower the survey rate from a "true value." ("Time telescoping" in the national survey and use of victim rather than offense rates for robberies are the major exceptions.)

As compared with the national estimates, the precinct studies, except for the one precinct in which the study was hampered by a riot, uniformly produced offense-rate estimates that had even greater divergence from those reported by the police departments for the same precincts. This was true even when survey-derived figures, which included only offenses against respondents that occurred in the precinct of residence, were compared with police rates that included nonresident victims. For all the precincts combined, the survey-derived estimates for Index offenses were about four times that of rates of offenses known to the police. Stated in forms of rates per 100,000 population, the city area estimates ranged from 10,000 to 24,000 -an altogether different order of magnitude from that of either city police data or national survey estimates.

Effects of Nonreporting to Police

The "dark figure" of crime usually is attributed primarily to the failure of citizens to report victimization to the police. In 38 per cent of the Index incidents tabulated in the national survey, the victims stated that the offense, to their knowledge, indeed did not become known to the police (see Table 5). But the national survey rate, estimated on the basis exclusively of incidents said to have been reported, was still 35 per cent greater than that of the UCR. The excess was greatest for burglaries ( 83 per cent). Auto thefts were the one exception. The survey-derived rate was 22 per cent lower than that of the UCR. This is to be expected, considering underenumeration by the survey and that auto thefts are, presumably, seldom left unreported to the police.

The possible interpretations of the discrepancy between survey and UCR estimates are, on the one hand, that the survey errs either (1) by overestimating crime, (2) by overestimating the reporting of crime to the police, or (3) by overclassifying crime; or, on the other hand, that UCR (1) fails to reflect all crimes reported to the police

TABLE 5-Estimated RATES OF INDEX Offenses Reported to the Police (NORC SURvey)

\begin{tabular}{|c|c|c|c|}
\hline Crime & $\begin{array}{c}\text { (a) } \\
\\
\text { NORC } \\
\text { SAMPLE } \\
\text { INCI- } \\
\text { DENTS } \\
\text { KNOWN } \\
\text { TO } \\
\text { POLICE } \\
\text { PER } \\
100,000 \\
\text { POPULA- } \\
\text { TION) }\end{array}$ & $\begin{array}{c}\text { (b) } \\
\text { UNIFORM } \\
\text { CRIME } \\
\text { REPORTS } \\
1965 \\
\text { (INDI- } \\
\text { VIDUAL } \\
\text { OR RESI- } \\
\text { DENTIAL } \\
\text { RATES } \\
\text { PER } \\
\text { 100,000 } \\
\text { POPULA- } \\
\text { TION) }\end{array}$ & $\begin{array}{c}\text { PER- } \\
\text { CENTAGE } \\
\text { DIF- } \\
\text { FERENCE } \\
\frac{(b-a)}{b}\end{array}$ \\
\hline Homicide & 3.0 & 5.1 & -42 \\
\hline Forcible Rape & 30.3 & 11.6 & +187 \\
\hline Robbery & 60.6 & 61.4 & -1 \\
\hline Aggravated Assault & 136.4 & 106.6 & +28 \\
\hline Burglary & 545.8 & 296.6 & +83 \\
\hline Larceny $(+\$ 50)$ & 360.8 & 267.4 & +35 \\
\hline Vehicle Theft & 175.8 & 226.0 & -22 \\
\hline Total & $1,312.7$ & 974.7 & $+35 \%$ \\
\hline
\end{tabular}


or (2) is affected by "down-classifying" of crimes.

Some of these possibilities were explored intensively in the BSSR study. For Part I offenses, the initial BSSR estimate of the number of offenses against adults occurring in their home precinct and reported to the police was approximately four times the number of Actual Offenses Known as reported $b y$ the police. A downward adjustment of the survey estimate equivalent to the over-all police "unfounding rate" was first applied, but this produces a reduction of only 4.4 per cent. Next, to allow for any possible errors in adjustments of police data to take into account offenses against organizations, minors, and nonresidents, survey estimates were compared with unadjusted police totals. The survey estimates were still more than twice the police total. Finally, to correct for possible differences in the way in which reports are classified by the police and by the survey, an estimate based on all survey incidents was compared with all classes of offenses in police statistics in which victimization could have been involved, plus all disorderly conduct charges, as well as all "Miscellaneous Incident (Non-Offense) Investigated" report categories which may have involved a victim complaint. The survey estimate for reported victimization of residents of the precinct was still more than a third again as large as the resulting total of police report entries.

For these areas of Washington, D.C., this first attempt at use of the survey method suggests that police statistics grossly underenumerate actual incidence. If respondent testimony may be accepted, the "dark figure" presumably involves the police not reporting as offenses those incidents that citizens report to them as such to a far greater extent than the failure of citizens to report victimization to the police.
A possible implication is that, at a minimum, full police reporting of citizen complaints would reveal half of the "dark figure" accessible to survey methods such as were employed in these studies.

It is possible that victims exaggerate the frequency of reporting to the police, in that it is "the right thing to do." Validation efforts would depend on the costly, as well as inconclusive, step of checking survey reports against police records. Considerable unreliability of testimony was indicated by a check in the opposite direction which was performed.

The Michigan study took advantage of a separate investigation it was conducting in which observers employed by the study accompanied police officers. They recorded transactions between the police and citizens. A sample of persons who had been observed to have reported on a victim experience to the police were interviewed several months after the event. The same interview schedule was used as that in the cross-sectional survey. In the follow-up interviews, over 20 per cent of these citizens failed to relate the incident which they had been observed reporting to the police. Should similar checks with more substantial samples confirm a rate of underreporting even close to this magnitude for crimes known to the police, even when followed up fairly soon after the event, the survey method would have to be regarded as dipping only shallowly and perhaps inaccurately into "dark figure" crimes.

\section{SUMmaRy AND CONClusions}

Respondents in a national survey report being victimized by crime more than twice as frequently as would be expected on the basis of the UCR "Crime Index." Surveys of residents of 
selected areas in three cities showed even sharper positive divergences in incidence from estimates based on police statistics.

Nonetheless, there are many indications that the survey interviews failed to measure exhaustively the victimization experienced by citizens. Many of these difficulties stem from the fact that most incidents of victimization, even many that are "serious" legally, are not highly salient experiences in a person's life and hence are not readily recalled in an interview. Often, respondents are also poor informants regarding offenses committed against others who live with them. Various steps in processing data to gain comparability with police statistics also reduce incidence estimates made by the surveys. Improved procedures in future applications of the survey method would yield higher incidence rates than in these first trials of the method.
Selectivity in the underenumeration makes the data unsuitable for comparative analysis of the objective victimization among various components of the population.

Victimization rates (victim-risk measures) are directly derivable from survey data. These rates are higher than offense rates, in that more than one person is affected by the majority of offenses. Offense statistics do not disclose the number of victims in crimes against property and, in the case of both property and person offenses, do not afford a ratio of victims to a pertinent population at risk.

Respondents claim that a high proportion of Index offenses became known to the police. If the respondents' reports are creditable, the "dark figure," at least in one city, is due in greater measure to police statistics not reflecting citizens' reports to the police than to nonreporting of crimes by citizens. 